\title{
Regulation of Enzymes for Erythrose 4-Phosphate Synthesis in Brevibacterium flavum
}

\author{
Shin-ichi Sugimoto and Isamu SHIIo \\ Central Research Laboratories of Ajinomoto Co., Inc.. \\ Kawasaki-ku, Kawasaki, Kanagawa 210, Japan \\ Received February 6, 1989
}

\begin{abstract}
Partially purified FBPase of $B$. favum exhibited Michaelis-Menten kinetics, with $K m$ of $22 \mu \mathrm{M}$ for $\mathrm{F} 1,6 \mathrm{P}_{2}$, but was inhibited by its substrate, $\mathrm{F} 1,6 \mathrm{P}_{2}$, at more than $30 \mu \mathrm{M}$. The inhibition reached $76 \%$ at $1.0 \mathrm{mM}$. FBPase was also competitively inhibited by $\mathrm{AMP}, \mathrm{S1}, 7 \mathrm{P}_{2}$, and $\mathrm{S} 7 \mathrm{P}$, the inhibitor constants being 32,23 , and $170 \mu \mathrm{M}$, respectively. The presence of $\mathrm{S} 1,7 \mathrm{P}_{2}$ in $B$. flavum was suggested by the presence of $A T P$-dependent $S 7 P$ kinase and $S 1,7 P_{2}$ aldolase activities, which corresponded to 27 and $89 \%$ of the $6 \mathrm{PFK}$ and $\mathrm{F1}, 6 \mathrm{P}_{2}$ aldolase activities, respectively. Transaldolase activity involved in S7P formation was also detected in cell-free extracts. Partially purified PGI showed $K m \mathrm{~s}$ of 1.4 and $0.54 \mathrm{mM}$ in the forward and reverse directions, respectively and was inhibited by E4P. The inhibition was of the mixed type with respect to $\mathrm{G} 6 \mathrm{P}$, with $K \mathrm{i}$ and $K \mathrm{i}^{\prime}$ of 32 and $260 \mu \mathrm{M}$, respectively. None of the metabolites tested inhibited TK. Whereas the specific activities of PGI and 6PFK were not affected by carbon sources in the culture medium, those of FBPase, IPFK, and TK were elevated 2.6, 2.6, and 1.7fold on growth on acetate, fructose, and citrate, respectively.
\end{abstract}

The regulatory mechanism for the synthesis of E4P, a biosynthetic precursor of aromatic amino acids, is interesting, especially in Brevibacterium flavum, since some mutants of this bacterium produce large amounts of various aromatic amino acids. ${ }^{1,2)}$

$\mathrm{E} 4 \mathrm{P}$ is synthesized through the TK reaction from F6P, an intermediate in glycolysis (Fig. 1). In the preliminary experiment, TK activity was not significantly affected by E4P or related metabolites, suggesting the possible regulation of PGI, which catalyzes the formation of F6P in glycolysis. The synthesis of E4P via the pentose phosphate pathway and its regulation were also possible, although this is a minor pathway in the glucose metabolism in this bacterium. ${ }^{3)}$ However, previous studies ${ }^{4,5}$ ) showed that G6PDH and 6-phosphogluconate dehydrogenase in this pathway are mainly regulated by NADPH, phosphoribosylpyro- phosphate, and some of the glycolytic intermediates.

The synthesis of E4P from fructose requires

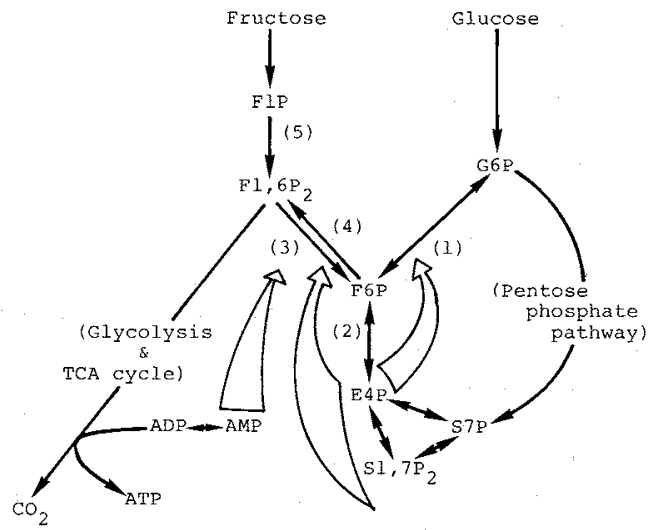

Fig. 1. Pathway for and Regulation of Erythrose 4Phosphate Synthesis in Brevibacterium flavum.

(1), PGI; (2), TK; (3). FBPase; (4), 6PFK; (5), IPFK. : $\bullet$, inhibition.

Abbreviations: FBPase, fructose bisphosphatase; PGI, phosphoglucoisomerase; TK, transketolase; 1 or 6 PFK, 1 or 6-phosphofructokinase; G6PDH, glucose-6-phosphate dehydrogenase; F1 or 6P, fructose 1- or 6-phosphate; F1,6 $\mathrm{P}_{2}$,

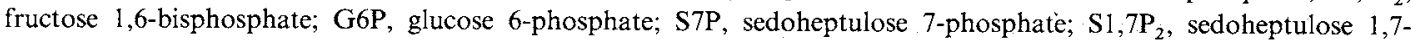
bisphosphate; E4P, erythrose 4-phosphate; Xu5P, xylulose 5-phosphate; R5P, ribose 5-phosphate; PEP, phosphoenolpyruvate. 
FBPase, in addition to TK, for the conversion of $\mathrm{F} 1,6 \mathrm{P}_{2}$ to $\mathrm{F} 6 \mathrm{P}$, since fructose is converted to $\mathrm{F} 1,6 \mathrm{P}_{2}$ via $\mathrm{F} 1 \mathrm{P}$ but not via $\mathrm{F} 6 \mathrm{P}$ in its central metabolism. ${ }^{6)}$ The same enzyme is also required for synthesis from acetate, citrate, and other organic acids.

This paper deals with the regulatory properties of TK, PGI, and FBPase in B. flavum, and reports feedback inhibition of PGI by E4P, and of FBPase by $\mathbf{S} 7 \mathrm{P}$ and $\mathrm{S} 1,7 \mathrm{P}_{2}$, as well as strong inhibition of FBPase by AMP.

\section{Materials and Methods}

Organism and culture media. Brevibacterium flavum No. 2247 (ATCC 14067) was used.

The compositions of Medium $40^{4)}$ and $41^{7 /}$ were given in previous papers.

Chemicals. F1, 6P 2, F6P, G6P, NADP, G6PDH (yeast), PGI (yeast), and a mixture of triosephosphate isomerase and glycerol-3-phosphate dehydrogenase (rabbit muscle) were purchased from Boehringer Mannheim. S1, 7P 2 , S7P, AMP, and E4P were from Sigma Chemical Co. Other chemicals used, see Table I, were purchased from Sigma Chemical Co., Boehringer Mannheim, or ICN Pharmaceuticals.

Enzyme preparations. FBPase: cells of strain No. 2247 cultured at $30^{\circ} \mathrm{C}$ for $24 \mathrm{hr}$ in Medium 40 containing acetic acid as a carbon source were harvested, washed twice with $0.2 \% \mathrm{KCl}$, suspended in $0.1 \mathrm{M}$ Tris $-\mathrm{HCl}$ buffer, $\mathrm{pH} 7.5$, and then sonically disrupted at $10 \mathrm{kc}$ for $20 \mathrm{~min}$. The supernatant solution of the sonicate obtained on centrifugation at $100,000 \times g$ for $60 \mathrm{~min}$ was applied on a hydroxyapatite column $(1.5 \times 15 \mathrm{~cm}$; Bio-Rad Bio-Gel HT) equilibrated with $0.05 \mathrm{M}$ Tris- $\mathrm{HCl}$ buffer, $\mathrm{pH} 7.5$, containing $1 \mathrm{mM} \mathrm{MnCl}$ and $10 \mathrm{~mm} \mathrm{MgCl}_{2}$. The column was washed with $25 \mathrm{ml}$ of the same buffer. FBPase was eluted with a potassium phosphate concentration gradient, which was formed with $110 \mathrm{ml}$ of the same buffer and that containing $0.2 \mathrm{M}$ potassium phosphate. Fractions of $2 \mathrm{ml}$ were collected. Fraction Nos. 56 to 58 were pooled and passed through a Sephadex G-25 column $(1.5 \times 10 \mathrm{~cm})$ equilibrated with $0.05 \mathrm{M}$ Tris- $\mathrm{HCl}$ buffer, $\mathrm{pH} 7.5$, containing $1 \mathrm{mM} \mathrm{MnCl}_{2}$ and $10 \mathrm{mM} \mathrm{MgCl}_{2}$, in order to remove inorganic phosphate.

PGI: The supernatant solution of the sonicate obtained above was applied on a DEAE cellulose column $(2.5 \times 21 \mathrm{~cm}$; Whatman DE-52) equilibrated with $0.05 \mathrm{M}$ Tris-HCl buffer, $\mathrm{pH}$ 7.5. The column was washed with $100 \mathrm{ml}$ of the same buffer. The enzyme was eluted with a $\mathrm{KCl}$ concentration gradient, which was formed with $500 \mathrm{ml}$ of the same buffer and that containing $0.5 \mathrm{M} \mathrm{KCl}$.
Fractions of $8 \mathrm{ml}$ were collected. Fraction Nos. 82 to 84 were pooled.

TK: The supernatant solution of the sonicate prepared from cells of strain No. 2247 grown for $24 \mathrm{hr}$ in Medium 40 containing citric acid as a carbon source was passed through a Sephadex G-25 column $(1.5 \times 10 \mathrm{~cm})$ equilibrated with $0.05 \mathrm{M}$ Tris- $\mathrm{HCl}$ buffer, $\mathrm{pH} 7.5$, and used as the TK preparation.

Enzyme assays. FBPase was assayed by masuring F6P formed, as described previously. ${ }^{6)}$ The reaction mixture contained $0.05 \mathrm{M}$ Tris- $\mathrm{HCl}$ buffer, $\mathrm{pH} 8.5,0.03 \mathrm{mM} \mathrm{Fl}$, $6 \mathrm{P}_{2}, 15 \mathrm{mM} \mathrm{MgCl}_{2}, 0.5 \mathrm{~mm} \mathrm{NADP}{ }^{+}, 5 \mu \mathrm{g}$ of $\mathrm{G} 6 \mathrm{PDH}$, $10 \mu \mathrm{g}$ of PGI, and the enzyme, in a total volume of $0.5 \mathrm{ml}$. The reaction was initiated by the addition of the enzyme and the formation of NADPH was followed by measuring the increase in absorbance at $340 \mathrm{~nm}$ with a Gilford 2600 Spectrophotometer at room temperature $\left(\mathrm{ca} .23^{\circ} \mathrm{C}\right)$. FBPase was assayed by measuring the liberation of inorganic phosphate from $\mathrm{Fl}, 6 \mathrm{P}_{2}$ using the same reaction mixture except for the omission of $\mathrm{NADP}^{+}$and coupling enzymes when indicated. The reaction was stopped after $10 \mathrm{~min}$ incubation at $30^{\circ} \mathrm{C}$ by the addition of $0.25 \mathrm{ml}$ of $10 \%$ trichloroacetic acid and the precipitate was removed by centrifugation. The amount of inorganic phosphate in the supernatant was determined by the method of Chen $e t$ $a .^{8)}$

PGI in the forward direction (from G6P to F6P) was colorimetrically assayed by determining F6P formed in the reaction mixture. The reaction mixture contained $0.05 \mathrm{M}$ Tris- $\mathrm{HCl}$ buffer, $\mathrm{pH} 8.0,4 \mathrm{~mm} \mathrm{G6P}$, and the enzyme, in a total volume of $0.5 \mathrm{ml}$. The reaction was stopped after $5 \mathrm{~min}$ incubation at $30^{\circ} \mathrm{C}$ by the addition of $2.0 \mathrm{ml}$ of the reagent of Roe. ${ }^{9}$ After $10 \mathrm{~min}$ incubation at $80^{\circ} \mathrm{C}$, the absorbance at $405 \mathrm{~nm}$ was measured. $\mathrm{PGI}$ in the reverse direction (from F6P to G6P) was assayed spectrophotometrically by following the reduction of $\mathrm{NADP}^{+}$at 340 $\mathrm{nm}$ in the presence of G6PDH. The reaction mixture was the same as that for the forward direction except that

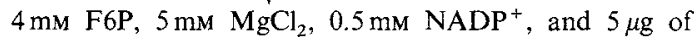
G6PDH were added instead of G6P. The reaction was started by the addition of the enzyme and the formation of NADPH was monitored at $340 \mathrm{~nm}$.

TK was assayed by measuring glyceraldehyde 3-phosphate formed. The reaction mixture contained $50 \mathrm{~mm}$ Tris- $\mathrm{HCl}$ buffer, $\mathrm{pH} 7.5,0.24 \mathrm{~mm} \mathrm{NADH}, 0.01 \mathrm{~mm}$ thiamine pyrophosphate, $1.0 \mathrm{~mm} \mathrm{MgCl}_{2}, 0.5 \mathrm{~mm} \mathrm{Xu} 5 \mathrm{P}$, $0.5 \mathrm{~mm}$ RPP, $20 \mu \mathrm{g}$ of the mixture of triosephosphate isomerase and glycerol-3-phosphate dehydrogenase, and the enzyme, in a total volume of $0.5 \mathrm{ml}$. The reaction was started by the addition of the enzyme and the decrease in $\mathrm{NADH}$ was monitored at $340 \mathrm{~nm}$.

Transaldolase was assayed by measuring glyceraldehyde 3-phosphate formed. The reaction mixture contained $50 \mathrm{~mm}$ Tris-HCl buffer, $\mathrm{pH} 7.5,5 \mathrm{~mm}$ EDTA, 0.5 mM E4P, $4.0 \mathrm{~mm}$ F6P $, 0.2 \mathrm{~mm} \mathrm{NADH}, 20 \mu \mathrm{g}$ of the mixture of triosephosphate isomerase and glycerol-3-phosphate dehy- 
drogenase, and the enzyme, in a total volume of $0.5 \mathrm{ml}$. The reaction was carried out as for the TK assay.

IPFK, 6PFK, and the amount of protein were assayed by the methods described previously. ${ }^{6)}$

\section{Results}

General properties of fructose bisphosphatase, phosphoglucoisomerase, and transketolase

FBPase activity was almost completely lost during DEAE-cellulose column chromatography under similar conditions to those for PGI purification given later. This seems due to the action of $\mathrm{KCl}$ in the column buffer, which strongly inhibited FBPase activity. However, when FBPase was stored in Tris- $\mathrm{HCl}$ buffer, $\mathrm{pH} 7.5$, at a low concentration $(1.5 \mathrm{mg}$ protein $/ \mathrm{ml}$ ) at $5{ }^{\circ} \mathrm{C}$ for $24 \mathrm{hr}$, it was fairly stable and only $9 \%$ of the original activity was lost. It was further stabilized by the presence of $1 \mathrm{~mm} \mathrm{Mn}^{2+}$ and $10 \mathrm{~mm} \mathrm{Mg}^{2+}$. The addition of ammonium sulfate and $\mathrm{KCl}$ enhanced the inactivation during storage. Therefore, the enzyme was partially purified, 4.6-fold with a $43 \%$ yield, by hydroxyapatite column chromatography in the presence of $\mathrm{Mn}^{2+}$ and $\mathrm{Mg}^{2+}$. The resultant preparation did not contain aldolase, PGI, or TK activity at all. On the other hand, PGI activity was quite stable in the presence of $\mathrm{KCl}$. The enzyme was partially purified by DEAE-cellulose column chromatography, in which it was eluted with $0.27 \mathrm{M}$ $\mathrm{KCl}$ and purified 4.3-fold, with a $31 \%$ yield. This preparation did not contain aldolase, FBPase, or TK activity. The properties of both the enzymes were examined using these partial purified preparations.

FBPase required $\mathrm{Mg}^{2+}$ as a cofactor for its activity. The activity became maximum at more than $5 \mathrm{~mm} \mathrm{Mg}^{2+}$. PGI did not require any cofactor.

The optimum pHs of the FBPase and PGI reactions were 8.5 with Tris- $\mathrm{HCl}$ buffer and 8.0 with either Tris- $\mathrm{HCl}$ or TES- $\mathrm{NaOH}$ buffer, respectively.

Figure 2 shows double reciprocal plots of the FBPase reaction rate against the substrate concentration. The plots gave a straight line at lower substrate concentrations, indicating that

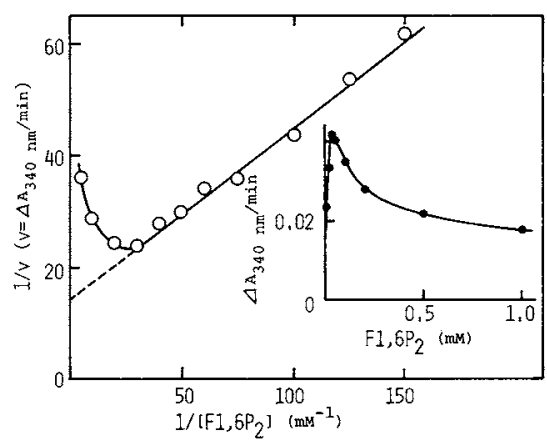

Fig. 2. Double Reciprocal Plots of the Fructose Bisphosphatase Reaction Rate against the F1, $6 \mathrm{P}_{2}$ Concentration.

FBPase was assayed under the standard conditions except that Tris- $\mathrm{HCl}$ buffer, $\mathrm{pH} 8.0$, and the indicated concentrations of $\mathrm{F} 1,6 \mathrm{P}_{2}$ were used.

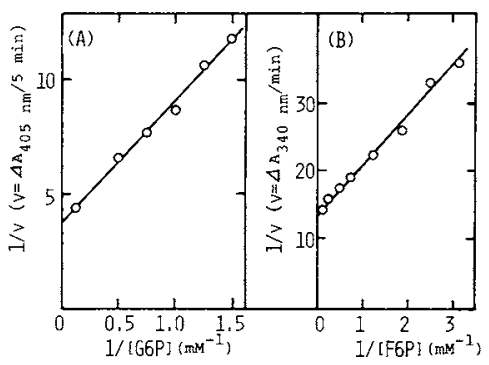

Fig. 3. Double Reciprocal Plots of the Phosphoglucoisomerase Reaction Rate against the Substrate Concentration.

PGI was assayed in the forward (A) and reverse (B) directions under the standard conditions except that

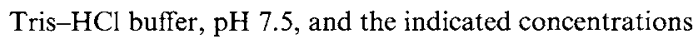
of $\mathrm{G} 6 \mathrm{P}$ or $\mathrm{F} 6 \mathrm{P}$ were used.

the reaction follows Michaelis-Menten kinetics. $K m$ with respect to FBP was estimated to be $22 \mu \mathrm{M}$. The activity was inhibited by the substrate at more than $30 \mu \mathrm{M}, 76 \%$ at $1 \mathrm{~mm} \mathrm{~F} 1$, $6 \mathrm{P}_{2}$, which was estimated by extrapolation of the linear plots at lower concentrations.

Figure 3 shows double reciprocal plots of the PGI reaction rate against the substrate concentration. The plots in both the forward and reverse directions gave straight lines. $\mathrm{Km}$ s with respect to G6P and F6P were estimated to be 1.4 and $0.54 \mathrm{mM}$, respectively, showing the higher affinity of the enzyme for F6P.

Double reciprocal plots of the TK reaction rate against the substrate concentration gave a 
straight line and apparent $K m \mathrm{~s}$ with respect to $\mathrm{Xu} 5 \mathrm{P}$ and R5P were estimated to be 0.11 and $1.2 \mathrm{~mm}$ in the presence of $1.2 \mathrm{~mm} \mathrm{R} 5 \mathrm{P}$ and

Table I. EFfects of Metabolites on Fructose Bisphosphatase, Phosphoglucoisomerase, and Transketolase ACtivities

FBPase was assayed under the conditions given in Fig. 2 , except that the concentration of $F 1,6 \mathrm{P}_{2}$ was $0.02 \mathrm{~mm}$. PGI was assayed under the conditions in Fig. 3, except that the concentration of G6P or F6P was 1.4 or $0.54 \mathrm{~mm}$, respectively. TK was assayed under the standard conditions, except that the concentrations of Xu5P and R5P were 0.11 and $1.2 \mathrm{~mm}$, respectively.

\begin{tabular}{|c|c|c|c|}
\hline \multirow{2}{*}{ Addition ( $1 \mathrm{~mm})$} & \multicolumn{3}{|c|}{ Relative activity $(\%)$} \\
\hline & FBPase & PGI & TK \\
\hline None & 100 & 100 & 100 \\
\hline Glucose 1-phosphate & $一$ & 95 & - \\
\hline G6P & $88^{b}$ & 一 & 98 \\
\hline Fructose 1-phosphate & 93 & $88^{c}$ & 101 \\
\hline F6P & $44^{b}$ & - & 87 \\
\hline $\mathrm{F} 1,6 \mathrm{P}_{2}$ & $24^{a}$ & $91^{c}$ & 87 \\
\hline Fructose 2,6-bisphosphate & 72 & $98^{c}$ & - \\
\hline Glyceraldehyde 3-phosphate & 50 & 94 & - \\
\hline 2-Phosphoglycerate & 85 & 97 & - \\
\hline 3-Phosphoglycerate & 85 & 95 & 92 \\
\hline PEP & 89 & 97 & 107 \\
\hline Pyruvate & 92 & 99 & 97 \\
\hline Acetyl-coenzyme A & 83 & 86 & 101 \\
\hline Citrate & 85 & 95 & 103 \\
\hline Oxaloacetate & 86 & 96 & 102 \\
\hline 6-Phosphogluconate & 70 & 55 & 113 \\
\hline $\mathrm{R} 5 \mathrm{P}$ & 83 & 100 & - \\
\hline Ribulose 5-phosphate & 89 & $63,61^{c}$ & 117 \\
\hline $\mathrm{Xu} 5 \mathrm{P}$ & 90 & $95,91^{c}$ & - \\
\hline E4P & 44 & $7.4,5.0^{c}$ & 145 \\
\hline S7P & 1.9 & $75,94^{c}$ & 81 \\
\hline $\mathrm{S} 1,7 \mathrm{P}_{2}$ & 1.6 & $77,97^{\mathrm{c}}$ & 83 \\
\hline Phosphoribosylpyrophosphate & 63 & 98 & 104 \\
\hline Phenylalanine & 109 & 92 & - \\
\hline ATP & 83 & 102 & - \\
\hline ADP & 79 & 93 & - \\
\hline AMP & 0.9 & 92 & - \\
\hline GTP & 28 & 100 & - \\
\hline GDP & 33 & 100 & - \\
\hline GMP & 62 & 98 & - \\
\hline ITP & 81 & 99 & - \\
\hline UTP & 79 & 100 & - \\
\hline CTP & 78 & 99 & - \\
\hline
\end{tabular}

a Estimated by dividing the activity at $1 \mathrm{mM} \mathrm{F} 1,6 \mathrm{P}_{2}$ by that extrapolated to $1 \mathrm{~mm}$ of the plots in Fig. 2 .

$b$ Assayed by measuring the liberation of inorganic phosphate.

c Assayed in the reverse direction.
$2 \mathrm{~mm} \mathrm{Xu} 5 \mathrm{P}$, respectively.

Regulation of fructose bisphosphatase, phosphoglucoisomerase, and transketolase activities

The effects of various metabolites on the FBPase, PGI, and TK activities were examined using modified assay systems with the same substrate concentrations as their $\mathrm{Km}$ values. As shown in Table I, FBPase was inhibited by $\mathrm{S} 7 \mathrm{P}$ and $\mathrm{E} 4 \mathrm{P}$, intermediates in the pentose phosphate pathway, AMP, an indi-

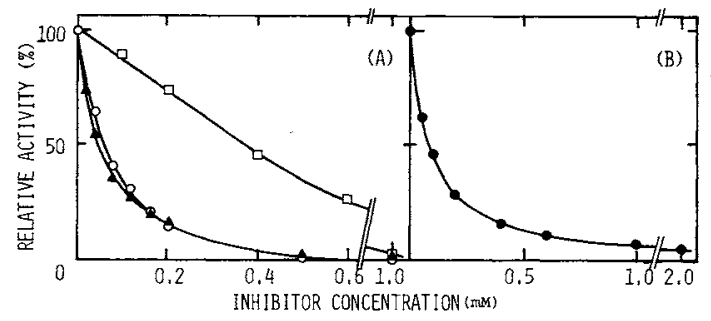

Fig. 4. Effects of the Inhibitor Concentrations on the Fructose Bisphosphatase and Phosphoglucoisomerase Activities.

FBPase (A) and PGI in the forward direction (B) were assayed under the same conditions as those in Table I in the presence of inhibitors. $-\mathrm{O}-\mathrm{AMP} ;-\mathbf{A}-\mathrm{S} 1,7 \mathrm{P}_{2}$; $-\square-$, S7P; - - - E4P

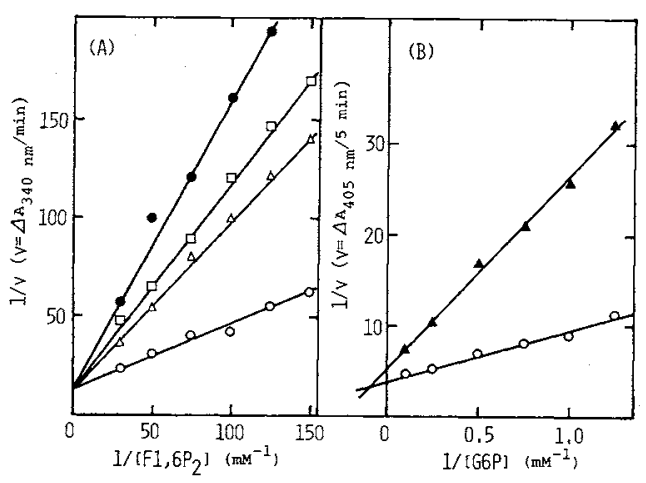

Fig. 5. Double Reciprocal Plots of the Fructose Bisphosphatase and Phosphoglucoisomerase Reaction Rates against the Substrate Concentrations in the Presence and Absence of Inhibitors.

FBPase (A) and PGI in the forward direction (B) were assayed under the same conditions those in Table I except for the substrate concentrations and the following additions. To the assay mixture, $0.5 \mathrm{~mm}$ S7P (A, - - - )

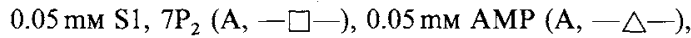
$0.1 \mathrm{~mm}$ E4P $(\mathrm{B},-\mathbf{A}-)$, or nothing $(-\mathrm{O}-)$ was added. 
cator for the energy charge, F6P, the reaction product, and $\mathrm{S} 1,7 \mathrm{P}_{2}$. Among them, AMP, S1, $7 \mathrm{P}_{2}$, and S7P showed strong inhibition, 99, 98, and $98 \%$, respectively. It was also inhibited by glyceraldehyde 3-phosphate, GTP, and GDP. On the other hand, PGI was inhibited $93 \%$ by $1 \mathrm{~mm}$ E4P. Among other metabolites tested, ribulose 5-phosphate and 6-phosphogluconate showed weak inhibitory effects.

Figure 4 shows the effects of the inhibitor concentrations on the enzyme activities. FBPase was completely inhibited by AMP, S1, $7 \mathrm{P}_{2}$, and S7P at more than $1 \mathrm{mM}$, and their concentrations giving $50 \%$ inhibition were estimated to be 45,60 , and $370 \mu \mathrm{M}$, respectively. On the contrary, the inhibition of PGI by E4P was not complete, but reached $95 \%$ at maximum. The concentration of E4P giving $50 \%$ inhibition was $90 \mu \mathrm{M}$. These results suggest the operation of these inhibitions in vivo. From double reciprocal plots of the reaction rate against the substrate concentrations in the

Table II. SEDOHEPTUloSE 7-PHOSPHATE KinASE AND Sedoheptulose 1, 7-Bisphosphate Aldolase IN Brevibacterium flavum

The supernatant solution of the sonicate prepared from cells of strain No. 2247 grown for $24 \mathrm{hr}$ in Medium 41 was passed through a Sephadex G-25 column $(1.5 \times 10 \mathrm{~cm})$ equilibrated with $0.05 \mathrm{M}$ Tris $-\mathrm{HCl}$ buffer, pH 7.5, (buffer A) for assay II and with Buffer A containing $0.1 \mathrm{M}$ ammonium sulfate, $10 \mathrm{mM} \mathrm{MgCl}_{2}$, and $2 \mathrm{~mm}$ EDTA (Buffer B) for assay I, and then used as the enzyme. The reaction mixture for assay I was the same as that for the 6PFK assay, except that the concentrations of S7P or F6P and ATP were $1.0 \mathrm{~mm}$, respectively. The reaction mixture for assay II contained $50 \mathrm{~mm}$ Tris $-\mathrm{HCl}$ buffer, pH 7.5, $4 \mathrm{mM} \mathrm{S1}, 7 \mathrm{P}_{2}$ or $\mathrm{F} 1,6 \mathrm{P}_{2}, 0.2 \mathrm{mM} \mathrm{NADH}$, $20 \mu \mathrm{g}$ of a mixture of glycerol-3-phosphate dehydrogenase and triose phosphate isomerase, and the enzyme, in a total volume of $0.5 \mathrm{ml}$.

\begin{tabular}{cccc}
\hline Assay & Substrate & Product measured & $\begin{array}{c}\text { Specific } \\
\text { activity } \\
\text { (nmol/min/mg } \\
\text { protein) }\end{array}$ \\
\hline I & S7P, ATP & ADP & 34 \\
& F6P, ATP & ADP & 124 \\
\hline II & S1, 7P 2 & Triose phosphates & 22 \\
& F1, 6P & Triose phosphates & 246 \\
\hline
\end{tabular}

presence and absence of the inhibitors (Fig. 5), the inhibition of FBPase by $\mathrm{S} 1,7 \mathrm{P}_{2}, \mathrm{AMP}$, and S7P was shown to be competitive with respect to $\mathrm{F} 1,6 \mathrm{P}_{2}$, the inhibitor constants being 23,32 , and $170 \mu \mathrm{M}$, respectively. The inhibition of PGI by E4P was of the mixed type with respect to $\mathrm{G} 6 \mathrm{P}$, the inhibitor constants, $K i$ and $K i^{\prime}$, being 32 and $260 \mu \mathrm{M}$, respectively.

$\mathrm{S} 7 \mathrm{P}$ seems to be present in vivo, since the pentose phosphate pathway has been shown to operate in this bacterium. ${ }^{3)}$ In fact, the activity of TK, which catalyzes the formation of S7P from $\mathrm{R} 5 \mathrm{P}$ and $\mathrm{Xu} 5 \mathrm{P}$, and that of transaldolase, which catalyzes the formation of S7P from E4P and F6P, were observed, the specific activities being 48 and $87 \mathrm{nmol} / \mathrm{min} / \mathrm{mg}$ protein, in cell-free extracts of $B$. flavum No. 2247 , respectively.

$\mathrm{S} 1,7 \mathrm{P}_{2}$ is not an intermediate of the pentose phosphate pathway. However, as shown in Table II, S7P-dependent ADP formation from ATP was observed in cell-free extracts, suggesting the presence of S7P kinase activity, which forms $\mathrm{S} 1,7 \mathrm{P}_{2}$ from $\mathrm{S} 7 \mathrm{P}$ and ATP. The activity corresponded to $27 \%$ of the F6Pdependent 6 PFK activity. The activity of aldolase, which catalyzes the reversible $\mathrm{S} 1,7 \mathrm{P}_{2}$ formation from E4P and triose phosphate, was

Table III. EFfects of Carbón SOURCes in the

Culture Medium on the Activities of Fructose Bisphosphatase, Phosphoglucoisomerase, Transketolase, 6-Phosphofructokinase, AND 1-PHOSPHOFRUCTOKINASE

The enzymes were prepared from cells of strain No. 2247 grown for $24 \mathrm{hr}$ in Medium 40 containing glucose, fructose, acetate, or citrate as a carbon source by the method described in Table II. The buffers used for Sephadex column equilibration were Buffer A for the FBPase, PGI, TK, and 1PFK assays, and Buffer B for the 6PFK assay.

\begin{tabular}{lcccccc}
\hline \multirow{2}{*}{$\begin{array}{l}\text { Carbon } \\
\text { source }\end{array}$} & $\begin{array}{c}\text { Growth } \\
\left(A_{562 \mathrm{~nm}}\right)\end{array}$ & \multicolumn{5}{c}{ Specific activity } \\
\cline { 3 - 7 } & & FBPase & PGI & TK & 6PFK & 1PFK \\
\hline Glucose & 0.405 & 41 & 814 & 42 & 234 & 116 \\
Fructose & 0.358 & 34 & 965 & 48 & 205 & 298 \\
Acetate & 0.425 & 108 & 799 & 64 & 280 & 113 \\
Citrate & 0.360 & - & - & 72 & - & - \\
\hline
\end{tabular}

a $\mathrm{nmol} / \mathrm{min} / \mathrm{mg}$ protein. 
also detected on measuring the formation of triose phosphate from $\mathrm{S} 1,7 \mathrm{P}_{2}$, and corresponded to $8.9 \%$ of the aldolase activity for $\mathrm{F} 1,6 \mathrm{P}_{2}$ as a substrate. These results suggest the presence of $\mathrm{S} 1,7 \mathrm{P}_{2}$ in vivo and, furthermore, that $\mathrm{S} 1,7 \mathrm{P}_{2}$ is a regulator of FBPase activity. On the other hand, the FBPase preparation used in this study also exhibited inorganic phosphate-liberating activity for $\mathrm{S} 1,7 \mathrm{P}_{2}$, which corresponded to $87 \%$ of that for $\mathrm{F} 1$, $6 \mathrm{P}_{2}$, suggesting that $\mathrm{S} 1,7 \mathrm{P}_{2}$ acts as a substrate analog for FBPase.

As shown in Table I, TK activity was not significantly inhibited by any of the metabolites tested. The activity was slightly enhanced by E4P, suggesting that the enzyme catalyzed the formation of glyceraldehyde 3phosphate from E4P as a substrate.

\section{Regulation of enzyme synthesis}

Table III shows the effects of carbon sources in the medium on the activities of FBPase, PGI, TK, 6PFK, and IPFK. The specific activities of PGI and 6PFK were scarcely affected by the carbon sources. However, when grown on acetate or fructose as a carbon source, FBPase and 1PFK showed 2.6- and 2.6-fold higher activity than when grown on the other carbon sources, indicating the induction of these enzymes by acetate and fructose, respectively. This also suggests that FBPase and 1PFK play important roles in gluconeogenesis and fructose metabolism, respectively. TK activity was also elevated 1.5 and 1.7-fold on growth on acetate and citrate, respectively.

\section{Discussion}

FBPase of B. flavum was found to be strongly inhibited by AMP, F1, 6P $2, \mathrm{~S} 7 \mathrm{P}$, and $\mathrm{S} 1$, $7 \mathrm{P}_{2}$ in the present study (Fig. 1). Since the concentrations of the former two inhibitors seem to be increased by operation of glycolysis, FBPase activity is being under depression by these inhibitions when glycolysis is operating. As $6 \mathrm{PFK}$ is not susceptible to the regulation reported in other microorganisms and has a high Michaelis constant for F6P, ${ }^{3)}$ it can be concluded that a futile cycle between $\mathrm{F} 6 \mathrm{P}$ and $\mathrm{F} 1,6 \mathrm{P}_{2}$, which is formed by $6 \mathrm{PFK}$ and FBPase, is regulated by the inhibition of FBPase during glycolysis and the high $\mathrm{Km}$ of 6PFK during gluconeogenesis. Inhibition by AMP and $F 1,6 P_{2}$ has been reported in various microorganisms. ${ }^{10}$ In particular, the Bacillus enzyme $^{11,12)}$ is highly sensitive to AMP inhibition $(K i, 2 \mu \mathrm{M})$. Therefore, since it was completely inhibited by AMP under various physiological conditions, the inhibition by AMP does not seem to be actually effective in the regulation of FBPase activity. The overcoming effect of PEP as to the AMP inhibition has been reported to play rather an important role in the regulation mechanism. In B. flavum, PEP neither activates FBPase nor overcomes the AMP inhibition. However, the B. flavum enzyme was less sensitive to the inhibition than the Bacillus enzyme. This suggests that the inhibition by AMP acts as a regulation mechanism in itself.

The inhibition of FBPase by S7P and S1, $7 \mathrm{P}_{2}$ seems to be a means of feedback control for the biosynthesis of E4P and other intermediates in the pentose phosphate pathway in the metabolism of fructose, acetate, and other organic acids. Whereas inhibition by S1, $7 \mathrm{P}_{2}$ has been reported in a photosynthetic bacterium, Rhodopseudomonas palustris, ${ }^{13)}$ the effect of S7P has not been examined in any other microorganisms. ${ }^{10)}$

On the other hand, the inhibition of PGI by E4P would be regarded as a means of feedback control of E4P biosynthesis in glucose metabolism. This inhibition does not seem to disturb the central metabolism of glucose, if F6P, the product of the PGI reaction, is in equilibrium with E4P via the TK reaction. PGI of yeast ${ }^{14)}$ has been reported to be inhibited by E4P. Moreover, 6-phosphogluconate, ribulose 5-phosphate, and R5P are also potent inhibitors in this microorganism. Their inhibitions were competitive with respect to the substrate, unlike that of the B. flavum enzyme, and the yeast enzyme was highly senstive to the E4P inhibition $(K i, 2 \mu \mathrm{M}){ }^{15}{ }^{15}$ 
The production of L-phenylalanine by a $B$. flavum mutant was seriously reduced when it was cultured on fructose as a carbon source, compared with on glucose, whereas that of $\mathrm{L}-$ glutamic acid was not. ${ }^{16,17)}$ This seems due to the different regulation of the synthesis of E4P, one of the precusors of L-phenylalanine biosynthesis in fructose metabolism. Contrary to this, L-glutamic acid biosynthesis does not require $\mathrm{E} 4 \mathrm{P}$ as a precursor. Thus, the reduction in L-phenylalanine production on cultivation on fructose can be attributed to the following. When fructose as well as glucose is actively catabolized, the intracellular concentrations of AMP and F1, 6P 2 seem to be elevated. As they are strong inhibitors of FBPase, it is very likely that the concentration of F6P stays at a low level and the metabolic flow from F6P towards E4P is reduced.

Acknowledgments. The authors are indebted to Drs. Y. Komachiya, R. Tsugawa, and I. Maeda for their encouragement during this work.

\section{References}

1) I. Shiio, S. Sugimoto and K. Kawamura, Agric. Biol. Chem., 48, 2073 (1984).

2) I. Shiio, S. Sugimoto and K. Kawamura, Agric. Biol. Chem., 52, 2247 (1988).
3) I. Shiio, S. Otsuka and T. Tsunoda, J. Biochem., 47, 414 (1960).

4) S. Sugimoto and I. Shiio, Agric. Biol. Chem., 51, 101 (1987).

5) S. Sugimoto and I. Shiio, Agric. Biol. Chem., 51, 1257 (1987).

6) S. Sugimoto and I. Shiio, Agric. Biol Chem., 53, 1261 (1989).

7) M. Mori and I. Shiio, Agric. Biol. Chem., 51, 129 (1987).

8) P. S. Chen, Jr., T. Y. Toribara and H. Warner, Anal. Chem., 28, 1756 (1956).

9) J. H. Roe, J. Biol. Chem., 107, 15 (1934).

10) G. A. Tejwani, in "Advances in Enzymology," Vol 54, ed. by A. Meister, Academic Press, New York, 1983, pp. $121-194$.

11) D. J. Opheim and R. W. Bernlohr, J. Biol. Chem., 250, 3024 (1975).

12) Y. Fujita and E. Freese, J. Biol. Chem., 254, 5340 (1979).

13) C. F. Springgate and C. S. Stachow, Arch. Biochem. Biophys., 152, 13 (1972).

14) M. Salas, E. Vinuela and A. Sols, J. Biol. Chem., 240, 561 (1965).

15) E. A. Noltmann, in "The Enzymes," Vol. VI, ed. by P. D. Boyer, Academic Press, New York, 1972, pp. $271 \sim 354$.

16) I. Shiio, S. Sugimoto, and K. Kawamura, Abstracts of Papers, the 14th International Congress of Biochemistry, Vol. 1, Prague, July, 1988, p. 66.

17) S. Sugimoto and I. Shiio, Abstract of Papers, the Annual Meeting of the Agricultural and Chemical Society of Japan, Niigata, April, 1989, p. 342. 